Dr. 2011

ORNL/TM-7136

\section{OAK RIDGE NATIONAL LABORATORY}

\section{UNION \\ CARBIDE}

\author{
R. A* Lillie \\ T. A. Gabriel \\ B. L. Bishop \\ V. C. Baker
}

OPERATED BY

UNION CARBIDE CORPORATION FOR THE UNITED STATES DEPARTMENT OF ENERGY 


\section{DISCLAIMER}

This report was prepared as an account of work sponsored by an agency of the United States Government. Neither the United States Government nor any agency Thereof, nor any of their employees, makes any warranty, express or implied, or assumes any legal liability or responsibility for the accuracy, completeness, or usefulness of any information, apparatus, product, or process disclosed, or represents that its use would not infringe privately owned rights. Reference herein to any specific commercial product, process, or service by trade name, trademark, manufacturer, or otherwise does not necessarily constitute or imply its endorsement, recommendation, or favoring by the United States Government or any agency thereof. The views and opinions of authors expressed herein do not necessarily state or reflect those of the United States Government or any agency thereof. 


\section{DISCLAIMER}

Portions of this document may be illegible in electronic image products. Images are produced from the best available original document. 
Printed in the United States of America. Available from National Technical Information Service

U.S. Department of Commerce

5285 Port Royal Road, Springfield, Virginia 22161

NTIS price codes-Printed Copy: A03; Microfiche A01

This report was prepared as an account of work sponsored by an agency of the United States Government. Neither the United States Government nor any agency thereof, nor any of their employees, makes any warranty, express or implied, or assumes any legal liability or responsibility for the accuracy, completeness, or usefulness of any informatinn, apnaratıs, product, or procese disclosod, or represents that its use would not infringe privately owned rights. Reference herein to any specific commercial product, process, or service by trade name, trademark, manufacturer, or otherwise, does not necessarily constitute or imply its endorsement, recommendation, or favoring by the United States Government or any agency thereof. The views and opinions of authors cxpressed herein do not necessarily state or reflect those of the United States Government or any agency thereof. 
Contract No. W-7405-eng-26

Engineering Physics Division

\title{
ONE-DIMENSIONAL GAMMA RAY AND PHOTONEUTRON SHIELDING CALCULATIONS FOR THE EBT-P*
}

\author{
R. A. Lillie \\ T. A. Gabriel \\ B. L. Bishop ${ }^{+}$ \\ V. C. Baker ${ }^{+}$ \\ * Submitted for \\ Journal publication \\ ${ }^{+}$Computer Sciences Division \\ tPresent address: General Dynamics, \\ Pomona, CA 91766.
}

Date Published - November 1980

NOTICE This document contains information of a preliminary nature. it is subject to revision or correction and therefore does not represent a final report.

OAK RIDGE NATIONAL LABORATORY

Oak Ridge, Tennessee 37830

operated by

UNION CARBIDE CORPORATION

for the

DEPARTMENT OF ENERGY 


\section{THIS PAGE}

\section{WAS INTENTIONALLY LEFT BLANK}


TABLE OF CONTENTS

Chapter

Abstract

I. INTRODUCTION

I I. CALCULATIONAL METHODS

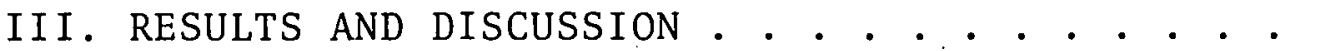

A. Bremsstrahlung Spectra . . . . . . . . .

B. Coil Heating . . . . . . . . . . . . . .

C. Biological Dose Rates . . . . . . . .
Page

$\mathrm{v}$

1

1.

11

11

16

21

29 
THIS PAGE

\section{WAS INTENTIONALLY LEFT BLANK}




\section{ABSTRACT}

One-dimensional radiation transport calculations have been performed to obtain estimates of the nuclear heat loads and biological dose rates due to bremsstrahlung gamma rays and photoneutrons in the EBT:P. The bremsstrahlung gamma rays arise because of electron impingement upon the magnetic coil assemblies and these gamma rays in turn produce photoneutrons through interactions in the high $\mathrm{Z}$ shielding. materials. For a 1 MW electron power $10 \mathrm{ss},{ }^{238} \mathrm{U}$ and tungsten coil shieid thicknesses of approximately 22.5 and $27.3 \mathrm{~mm}$, respectively, were found sufficient to limit the nuclear heat load on a single superconducting coil to 10 watts. The estimated lead and concrete primary shield thicknesses required to reduce the biological dose rate due to bremsstrahlung gamma rays were calculated to be 0.318 and $1.92 \mathrm{~m}$, respectively. However, because of photoneutron production, lead by itself was not found to be an acceptable biological shield. 


\section{I . INTRODUCTION}

The induced gamma ray field from bremsstrahlung in the ELMO Bumpy Torus - proof of principle device (EBT-P) will be very intense due to the expected large loss of electrons on the magnetic coil assemblies and other components of this plasma device. Because of this intense gamma ray field and space limitations, high $Z$ coil shielding materials are required to ensure minimal gamma ray heating in the superconducting cryogenic coils. In addition, the gamma rays will produce secondary neutrons via photoneutron reactions in the high $Z$ materials and these neutrons together with the gamma rays will create a significant biological hazard.

In this paper, the results from one-dimensional radiation transport calculations, in which the nuclear heat loads in the superconducting coils were estimated, are presented for several coil shield thicknesses. Also, one-dimensional results which indicate the level of biological dose are given for varying thicknesses of either lead or concrete that have been proposed for the primary shielding. The calculational methods are described in section. II and the calculated results are presented and discussed in Section III.

\section{I . CALCULATIONAL METHODS}

The one-dimensional models used to describe the EBT-P are shown in Fig. 1. The geometric model designated for the coil heating calculations, Fig. 1a, was also used to generate the 


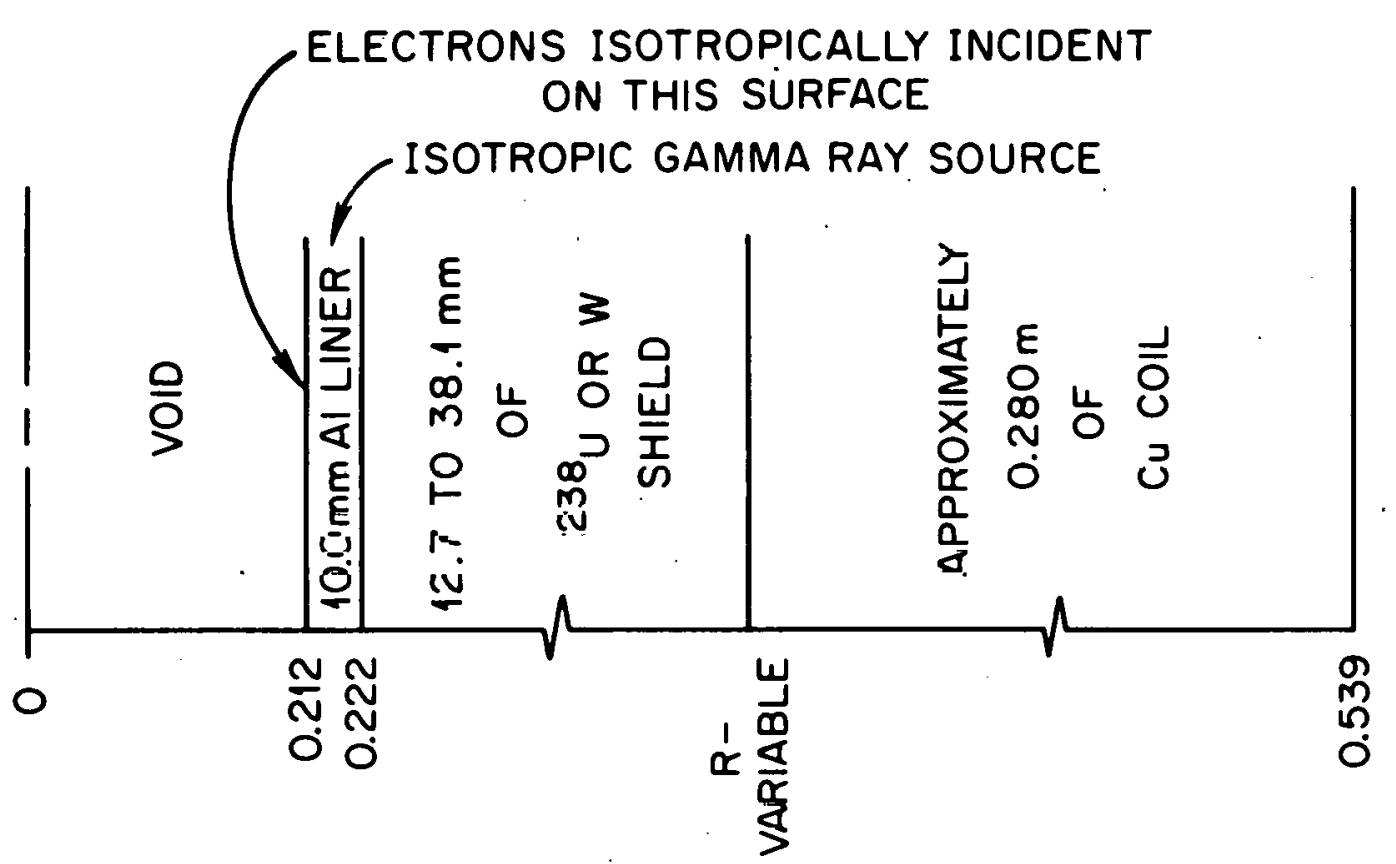

ORNL-DWG 79-19531R

MINOR RADIUS $(\mathrm{m})$

(a) GEOMETRIC MODEL FOR COIL HEATING CALCULATIONS

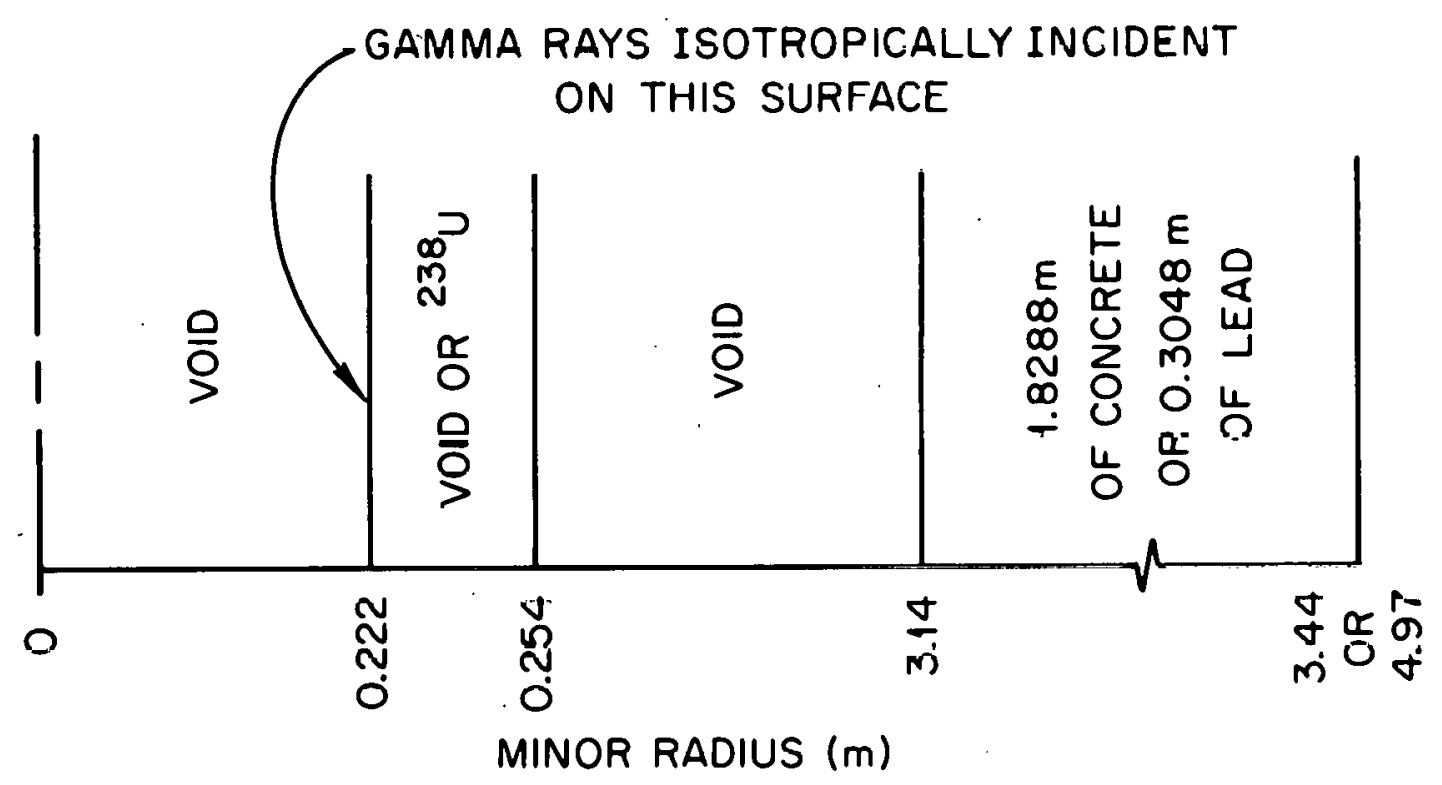

(b) GEOMETRIC MODEL FOR BIOLOGICAL DOSE CALCULATIONS

Fig. 1. One-dimensional geometric models. 
bremsstrahlung spectra. In this model, the $10.0 \mathrm{~mm}$ thick aluminum coil liner, 12.7 to $38.1 \mathrm{~mm}$ thick ${ }^{238_{\mathrm{U}}}$ or tungsten coil shield and the coil, which for simplicity was assumed to be purely $\mathrm{Cu}$, were approximated as a series of infinitely long concentric cylinders about the toroidal axis of the EBT-P. The biological dose calculations were performed using the geometric model shown in Fig. 1b. The region denoted as either void or ${ }^{238} \mathrm{U}$ was included in this model to obtain the biological dose for varying thicknesses of lead and concrete with and without $31.8 \mathrm{~mm}$ of ${ }^{238} \mathrm{U}$ coil shielding.

As shown in Fig. 1a, the electron loss on the magnetic coil assemblies was approximated by assuming these electrons to be isotropically incident on the inner face of the aluminum coil liner. The transport of these electrons and subsequent generation of the bremsstrahlung gamma ray spectra was carried out using the EGS-PEGS code system. ${ }^{1}$ This Monte Carlo code package takes into account all physical processes which are important in the transport of electrons through matter. These processes include Compton scattering, pair production, photoelectric effect, Moller scattering, Bhabha scattering, electron-positron annihilation, bremsstrahlung, and, through the use of the continuous slowing down approximation, the energy loss of the charged particles.

The gamma rays from bremsstrahlung could have been transported using EGS-PEGS, except for the large uncertainties associated with Monte Carlo methods in deep penetration 
calculations. To circumvent this problem, the actual coil heating and biological shielding calculations were performed with the one-dimensional discrete ordinates code ANISN. ${ }^{2}$ This code has been used extensively for one-dimensional shielding calculations and is very applicable to deep penetration problems. In the coil heating calculations, the gamma ray source spectra were placed at the center of the aluminum coil liner as shown in Fig. 1a. In the biological dose calculations, these same gamma ray source spectra were placed at the location of the aluminum coil liner-coil shield interface as denoted in Fig. 1b. For both sets of calculations the angular distributions of the gamma ray sources were isotropic since all electron sources were assumed to be isotropic.

The magnitudes and energy distributions of the gamma ray sources were obtained by considering a specific electron loss distribution. In this work, the rate at which electrons are lost from the plasma was assumed to be proportional to a Maxwe11ian distribution weighted by $\mathrm{E}^{-3 / 2}$, i.e.,

$$
L\left(E_{e}, K T\right)-\Lambda(K T) E X P\left(-E_{e} / K T\right) / E_{e} \cdot
$$

where $E_{e}$ represents the electron energy, $T$ represents the plasma temperature, and $A(K T)$ is simply a normalization constant. In a11 of the calculations performed here, the total power associated with electron loss was taken as 1 MW which yields a normalization constant of $\mathrm{A}(\mathrm{KT})=6.24 \times 10^{18} / \mathrm{KT}$. 
Since very low energy electrons can produce only low energy gamma rays and these low energy gamma rays cannot contribute significantly to either the coil heating or biological dose, only electrons with energies greater than $0.239 \mathrm{MeV}$ were considered. For KT values of $1.0,1.5$, and $2.0 \mathrm{MeV}$, the total number of electrons lost from the system per second with energies greater than $0.239 \mathrm{MeV}$ are $5.99 \times 10^{18}, 5.37 \times 10^{18}$, and $4.80 \times 10^{18}$, respectively. These numbers were obtained by integrating the loss distribution up to electron energies of $10 \mathrm{MeV}$. For a $\mathrm{KT}$ of $2.0 \mathrm{MeV}$, the integration was also carried out up to $20 \mathrm{MeV}$ which produced a loss rate of $4.81 \times 10^{18}$ electrons/ sec. This extension of the integral for a KT of $2.0 \mathrm{MeV}$ (which will be designated as $\mathrm{KT}=2.0^{*} \mathrm{MeV}$ in the remainder of this paper) was performed by assuming the bremsstrahlung spectra from electrons with energies greater than $10 \mathrm{MeV}$ were the same as the spectrum produced by $10 \mathrm{MeV}$ electrons.

The bremsstrahlung gamma ray spectra due to the electron loss distribution given by Eq. (1) for the various values of KT were obtained by performing a series of EGS-PEGS calculations. In these calculations, electrons with total energies, i.e., kinetic plus rest mass energies, varying between 1.0 and $10 \mathrm{MeV}$ in increments of $0.5 \mathrm{MeV}$ were transported to generate nineteen discrete bremsstrahlung spectra. With these spectra, the cumulative bremsstrahlung spectra for the various values of KT were numerically obtained by evaluating the following expression: 


$$
h\left(E_{\gamma}, K T\right)=\frac{\int_{0.239}^{10 M e V} g\left(E_{\gamma}, E_{e}\right) L\left(E_{e}, K T\right) d E_{e}}{\int_{0.239}^{10 M e V} L\left(E_{e}, K T\right) d E_{e}}
$$

where $g\left(E_{\gamma}, E_{e}\right)$ represents the bremsstrahlung spectrum produced by one electron at energy $E_{e}$ and $L\left(E_{e}, K T\right)$ is the electron loss distribution defined by Eq. (1). The denominator in Eq. (2) simply normalizes the cumulative bremstrahlung spectrum. Thus, $h\left(E_{\gamma}, K T\right)$ has units of gamma rays/sec produced per electron/sec lost from the plasma.

With the above gamma ray spectra as input, ANISN calculations using the geometric models shown in Fig. 1 were performcd to obtain cstimates of the coil heating and biological dose due to the gamma rays. These calculations were carried out using an $\mathrm{S}_{8}$ angular quadrature and the DLC-3I cross section library. ${ }^{3}$ This library contains 37 -neutron and 21 -gammaray energy groups with a $\mathrm{P}_{3}$ Legendre approximation of the group to group transfer cross sections. In all of the calculations, the theoretical atom densitities of $\mathrm{Al}, \mathrm{W},{ }^{238} \mathrm{U}, \mathrm{Cu}$ and $\mathrm{Pb}$ were used to describe the aluminum liner, tungsten and uranium coil shields, copper coils, and the lead biological shicld, respectively. The concrete biological shield was taken to be Tower Shielding Facility concrete. ${ }^{4}$ Because of the relatively high energies of the bremsstrahlung gamma rays, i.e., greater than $6 \mathrm{MeV}$, secondary 
neutrons are produced via $(\gamma, x N)$ and $(\gamma, F)$ reactions in ${ }^{238} \mathrm{U}$ and $(\gamma, \mathrm{xN})$ reactions in tungsten and lead. These secondary neutrons in turn give rise to secondary gamma rays through high energy neutron inelastic collisions and low energy neutron captures and these secondary particles also contribute to the coil heating and biological dose.

The magnitude of the secondary neutron production due to $(\gamma, x N)$ and $(\gamma, F)$ reactions in the ${ }^{238} \mathrm{U}$ coil shield was obtained using the following expressions:

$$
N_{\gamma, x N}=\int_{6.5}^{20 \mathrm{MeV}} \Phi_{\gamma}(E)\left[\Sigma_{\gamma, N}(E)+2 \Sigma_{\gamma, 2 N}(E)\right] d E
$$

and

$$
\mathrm{N}_{\gamma, F}=\int^{20 \mathrm{MeV}} \Phi_{\gamma}(E) \nu(E) \Sigma_{\gamma, F}(E) d E
$$

$$
6.5
$$

where $\Sigma_{\gamma, N}(E), \Sigma_{\gamma, 2 N}(E)$, and $\Sigma_{\gamma, F}(E)$ are the energy-dependent neutron macroscopic cross sections for $(\gamma, N),(\gamma, 2 N)$, and $(\gamma, F)$ reactions, respectively, in ${ }^{238} U$, and $\nu(E)$ is the neutron multiplicity for fissions produced by gamma rays at energy E. The macroscopic production cross sections were obtained by folding the ${ }^{238} \mathrm{U}$ theoretical atom density with the microscopic production data contained in a compilation of photoneutron cross sections by Berman. ${ }^{5}$ The neutron multiplicity was assumed to be the same as that for fissions produced by neutrons of energy $E-E_{b}$, where $E_{b}$ corresponds to the binding energy of 
the last neutron in ${ }^{239} \mathrm{U}$.

The spatially averaged gamma ray fluence at energy $E$, $\Phi_{\gamma}(E)$, in the ${ }^{238} \mathrm{U}$ was obtained by performing an additional EGS-PEGS calculation. The need for the additional EGS-PEGS calculation arose because the gamma ray transport cross section 1 ibrary ${ }^{3}$ used in the ANISN calculations did not extend above $14 \mathrm{MeV}$ and this energy corresponds roughly to the peak in the $(\gamma, \dot{x N})$ and $(\gamma, P)$ production cruss sections. The EGS-PEGS calculation was performed by sampling electrons up to $20 \mathrm{MeV}$ from a uniform energy distribution and weighting by the electron loss distribution given by Eq. (1) with a plasma temperature corresponding to $\mathrm{KT}=2.0 \mathrm{MeV}$. The gamma rays produced by these electrons were then transported within this same EGS-PEGS calculation to obtain the energy-dependent gamma ray fluence in a $31: 8 \mathrm{~mm}$ thick ${ }^{238} \mathrm{U}$ coil shield.

The neutron source spectrum for the $(\gamma, F)$ reactions in ${ }^{238} \mathrm{U}$ was assumed to be the same as that produced in neutron induced fission. This spectrum was taken directly from the DLC-31 cross section 1ibrary. The neutron source spectrum for the $(\gamma, x N)$ reactions in ${ }^{238} \mathrm{U}$ was obtained using a simple evaporation mode1, i.e.,

$$
N(E)=C E e^{-E / \theta}, \quad 0 \leq E \leq 14 \mathrm{MeV}
$$

where $C$ is simply a normalization constant and $\theta$ corresponds to an effective neutron evaporation energy. This energy is given by 6 


$$
\theta=\frac{\frac{3.22}{\sqrt{\mathrm{A}}} \int^{20 \mathrm{MeV}} 6.5 \Phi_{\gamma}(\mathrm{E}) \mathrm{E}^{1 / 2} \mathrm{dE}}{\int^{20 \mathrm{MeV}} \Phi_{\gamma}(\mathrm{E}) \mathrm{dE}}
$$

wherc A represents the atomic mass number of ${ }^{238} \mathrm{U}$.

The coil heating and biological dose due to the secondary neutrons from the ${ }^{238} \mathrm{U}$ coil shield were determined from addi tional ANISN calculations using the geometric models shown in Fig. 1. Scoping calculations indicated that the various nuclear reponses were insensitive to small spatial variations of the neutron sources, hence the secondary neutron sources were placed at the center of the ${ }^{238} \mathrm{U}$ coil shield. The neutrons and secondary gamma rays were transported in ANISN using the 37-neutron-21-gamma-ray energy cross section library noted above. In all of the calculations, the angular distribution. of the secondary photoneutron sources was taken to be isotropic.

The coil heating and biological dose due to $(\gamma, x N)$ reactions in a tungsten coil shield and the biological dose due to $(\gamma, x N)$ reactions in a lead primary shield were only estimated. The results obtained for the ${ }^{238} \mathrm{U}$ secondary neutrons, when compared with the corresponding results for the bremsstrahlung gamma rays, did not justify using the above procedure in determining the nuclear effects due to secondary neutrons from tungsten and lead. In fact, as evidenced in the next section, an order of magnitude error in the coil heating or biological dose due to photoneutrons from tungsten or lead will have 
little or no impact on the results of this study.

For the above reasons it was assumed that the energy distribution of the secondary neutrons produced in tungsten and lead was equivalent to the energy distribution of the photoneutrons produced in ${ }^{238} \mathrm{U}$. It was further assumed that the energy distribution of the spatially averaged gamma ray fluences in these materials were equivalent. The magnitudes of the gamma ray fluences in tungsten and lead were estimated by scaling the ${ }^{238} \mathrm{U}$ gamma ray fluence by the ratio of the appropriate $10 \mathrm{MeV}$ gamma ray fluences obtained from the ANISN coil heating and biological dose calculations for a plasma temperature corresponding to a KT of $2.0 * \mathrm{MeV}$. These fluences were then folded with the $(\gamma, x N)$ production cross sections 5 for tungsten and lead and the resulting photoneutrons were transported using ANISN.

The gamma ray heating kerma factors of $\mathrm{Al},{ }^{238} \mathrm{U}$, and $\mathrm{Cu}$ were taken from the Evaluated Photon Interaction Library ${ }^{7}$ and were processed into the proper gamma ray energy group structure using the SMUG module in the AMPX code system. ${ }^{8}$ The neutron fluence-to-dose conversion factors were obtained from the MACK IV library ${ }^{9}$ and the gamma ray fluence-to-dose factors were taken directly from the DLC-31 cross section library used in the ANISN calculations. 
III. RESULTS AND DISCUSSION

A. Bremsstrahlung Spectra

The discrete bremstrahlung spectra obtained from the EGS-PEGS calculations are given in Table I for a large range of electron energies. The gamma ray energy group structure corresponding to the 21-gamma-ray energy groups in the DLC-31 cross section library is also given in Table $I$. This group structure, which is fairly fine at low energies, covers the gamma ray energy range between 0.01 and $14.0 \mathrm{MeV}$. The spectra for each electron energy have been normalized per electron incident on the aluminum coil liner and the total number of gamma rays produced per incident electron is noted for each spectra.

The importance of each electron energy to the total bremsstrahlung gamma ray energy deposition rate in the superconducting coils is illustrated in Fig. 2 for several ${ }^{238} \mathrm{U}$ coil shield thicknesses. These results are normalized per incident electron per second and were obtained by performing separate ANISN calculations for each of the spectra listed in Table I. The increase in energy deposition rate with increasing electron energy is due to two effects. As the energy of the incident electrons increases, the number of gamma rays produced at a given energy increases and additional higher energy gamma rays are also produced.

The total energy deposition rate in the Cu coils due to bremsstrahlung gamma rays can be obtained by weighting the 
TABLE I

EREMSSTRAH_UNG SPECTRA. FOR GAMMA RAYS ABOVE 0.01 MEV (GAMMAA RAYS/ELECTRON)

\begin{tabular}{|c|c|c|c|c|c|c|c|}
\hline \multirow{2}{*}{$\begin{array}{l}\text { Gamma } \\
\text { Ray } \\
\text { Upper } \\
\text { Energy } \\
\text { (MeV) }\end{array}$} & \multicolumn{7}{|c|}{ Electron Energy (MeV) } \\
\hline & $0.489(1.0)^{\mathrm{a}}$ & $0.989(1.5)$ & $1.489(2.0)$ & $1.989(2.5)$ & $2.489(3.0)$ & $2.989(3.5)$ & $3.489(4.0)$ \\
\hline $\begin{array}{l}14 \\
10 \\
8 \\
7 \\
6 \\
5 \\
4 \\
3 \\
2.5 \\
2.0 \\
1.5 \\
1.0 \\
0.7 \\
0.45 \\
0.3 \\
0.15 \\
0.1 \\
.07 \\
.045 \\
.03 \\
.02\end{array}$ & $\begin{array}{l}0 \\
\\
\\
\\
1.20-3^{b} \\
4.80-3 \\
2.00-3 \\
4.00-3 \\
6.80-3 \\
6.00-3 \\
6.40-3 \\
8.00-3\end{array}$ & 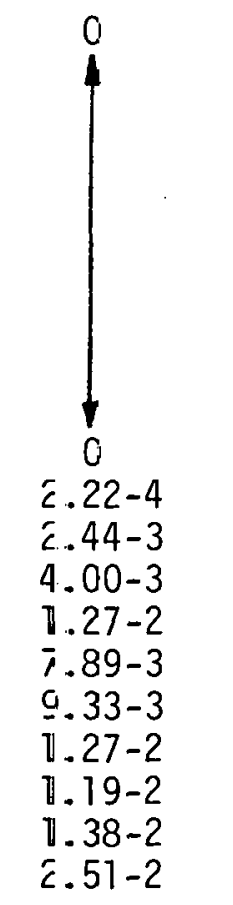 & $\begin{array}{l}0 \\
1 \\
0 \\
8.89-4 \\
1.89-3 \\
5.89-3 \\
7.33-3 \\
2.14-2 \\
1.50-2 \\
1.77-2 \\
2.46-2 \\
2.30-2 \\
2.36-2 \\
3.70-2\end{array}$ & $\begin{array}{c}0 \\
\mid \\
0 \\
5.56-4 \\
2.56-3 \\
5.89-3 \\
1.06-2 \\
1.34-2 \\
3.33-2 \\
2.12-2 \\
2.38-2 \\
2.36-2 \\
3.03-2 \\
3.32-2 \\
5.43-2\end{array}$ & $\begin{array}{l}0 \\
\uparrow \\
0 \\
1.11-4 \\
1.67-\tilde{z} \\
5.67-\tilde{z} \\
8.89-\tilde{z} \\
1.58-\tilde{c} \\
2.08-\tilde{c} \\
4.37-\tilde{c} \\
2.88-\tilde{c} \\
3.12-\tilde{c} \\
4.10-\tilde{c} \\
4.00-\tilde{c} \\
3.99-\tilde{c} \\
6.86-\tilde{c}\end{array}$ & $\begin{array}{c}0 \\
\\
0 \\
8.89-4 \\
3.22-3 \\
9.78-3 \\
1.49-2 \\
2.23-2 \\
2.74-2 \\
5.38-2 \\
3.86-2 \\
3.79-2 \\
4.98-2 \\
4.97-2 \\
5.29-2 \\
8.18-2\end{array}$ & $\begin{array}{l}0 \\
1 \\
0 \\
1.11-4 \\
5.56-4 \\
2.33-3 \\
4.22-3 \\
1.31-2 \\
1.67-2 \\
2.67-2 \\
2.88-2 \\
7.12-2 \\
4.51-2 \\
4.61-2 \\
5.83-2 \\
6.06-2 \\
5.97-2 \\
9.01-2\end{array}$ \\
\hline Total $\gamma^{\prime} s / e^{-}$ & $3.92-2$ & $11.00-1$ & $1.78-1$ & $2.58-1$ & $3.46-1$ & $4.43-1$ & $\begin{array}{l}5.24-1 \\
\text { tinued) }\end{array}$ \\
\hline
\end{tabular}


TABLE I (Cont'd)

BREMSSTRAHLUNG SPECTRA FOR GAMMA RAYS ABOVE 0.01. MEV (GAMMA RAYS/ELECTRON)

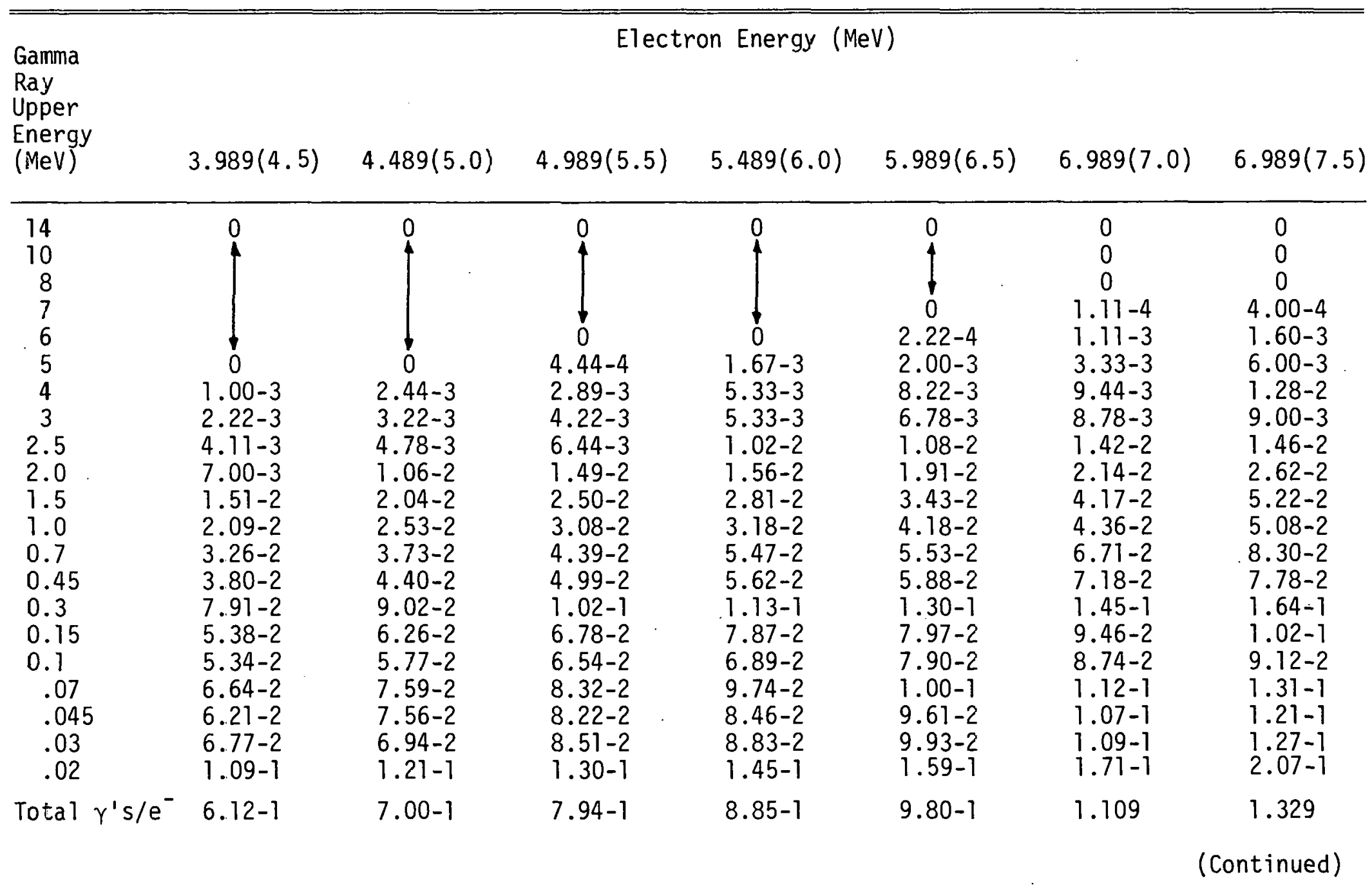


TABLE I (Cont'd)

BREMSSTRAHLUNG SPECTRA. FOR GAMMA RAYS ABOVE 0.CI MEV. (GAMMA. FAYS/ELECTRON)

\begin{tabular}{|c|c|c|c|c|c|}
\hline $\begin{array}{l}\text { Gamma } \\
\text { Ray } \\
\text { Upper } \\
\text { Energy } \\
\text { (MeV) }\end{array}$ & $7.489(8.0)$ & $7.989(8.5)$ & $\begin{array}{l}\text { Onergy (Me } \\
8.489(9.0)\end{array}$ & $8.989(9.5)$ & $9.489(10.0)$ \\
\hline $\begin{array}{l}14 \\
10 \\
8 \\
7 \\
6 \\
5 \\
4 \\
3 \\
2.5 \\
2.0 \\
1.5 \\
1.0 \\
0.7 \\
0.45 \\
0.3 \\
0.15 \\
0.1 \\
.07 \\
.045 \\
.03 \\
.02\end{array}$ & $\begin{array}{l}0 \\
0 \\
1.11-4 \\
1.11-3 \\
3.00-3 \\
5.78-3 \\
1.10-2 \\
1.16-2 \\
1.59-2 \\
2.92-2 \\
5.24-2 \\
5.53-2 \\
8.44-2 \\
9.40-2 \\
1.84-1 \\
1.21-1 \\
1.16-1 \\
1.46-1 \\
1.39-1 \\
1.41-1 \\
2.29-1\end{array}$ & $\begin{array}{c}0 \\
0 \\
4.00-4 \\
1.20-3 \\
4.40-3 \\
7.40-3 \\
1.74-2 \\
1.38-2 \\
2.14-2 \\
3.52-2 \\
5.46-2 \\
5.98-2 \\
1.02-1 \\
1.01-1 \\
2.06-1 \\
1.33-1 \\
1.26-1 \\
1.53-1 \\
1.54-1 \\
1.62-1 \\
2.68-1\end{array}$ & $\begin{array}{l}0 \\
0 \\
1.20-3 \\
1.80-3 \\
5.60-3 \\
8.60-3 \\
1.70-2 \\
1.82-2 \\
2.68-2 \\
4.02-2 \\
6.86-2 \\
7.74-2 \\
1.10-1 \\
1.17-1 \\
2.50-1 \\
1.51-1 \\
1.39-1 \\
1.85-1 \\
1.79-1 \\
1.95-1 \\
2.91-1\end{array}$ & $\begin{array}{c}0 \\
4.00-4 \\
1.20-3 \\
4.20-3 \\
5.60-3 \\
1.04-2 \\
2.08-2 \\
1.80-2 \\
2.54-2 \\
4.06-2 \\
8.42-2 \\
9.00-2 \\
1.25-1 \\
1.24-1 \\
2.55-1 \\
1.74-1 \\
1.61-1 \\
2.12-1 \\
2.05-1 \\
2.13-1 \\
3.16-1\end{array}$ & $\begin{array}{c}0 \\
6.00-4 \\
2.00-3 \\
3.80-3 \\
7.60-3 \\
1.32-2 \\
2.68-2 \\
2.12-2 \\
3.22-2 \\
5.10-2 \\
8.74-2 \\
9.90-2 \\
1.43-1 \\
1.45-1 \\
2.88-1 \\
1.96-1 \\
1.84-1 \\
2.22-1 \\
2.24-1 \\
2.17-1 \\
3.51-1\end{array}$ \\
\hline Total $\gamma^{\prime} s / e^{-}$ & 1.440 & 1.621 & 1.882 & 2.086 & 2.315 \\
\hline
\end{tabular}

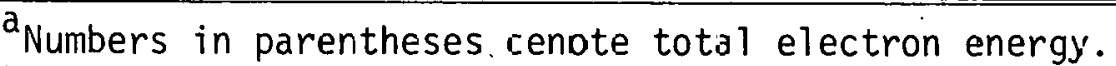

$b_{\text {Read as } 1.20 \times 10^{-3}}$
} 


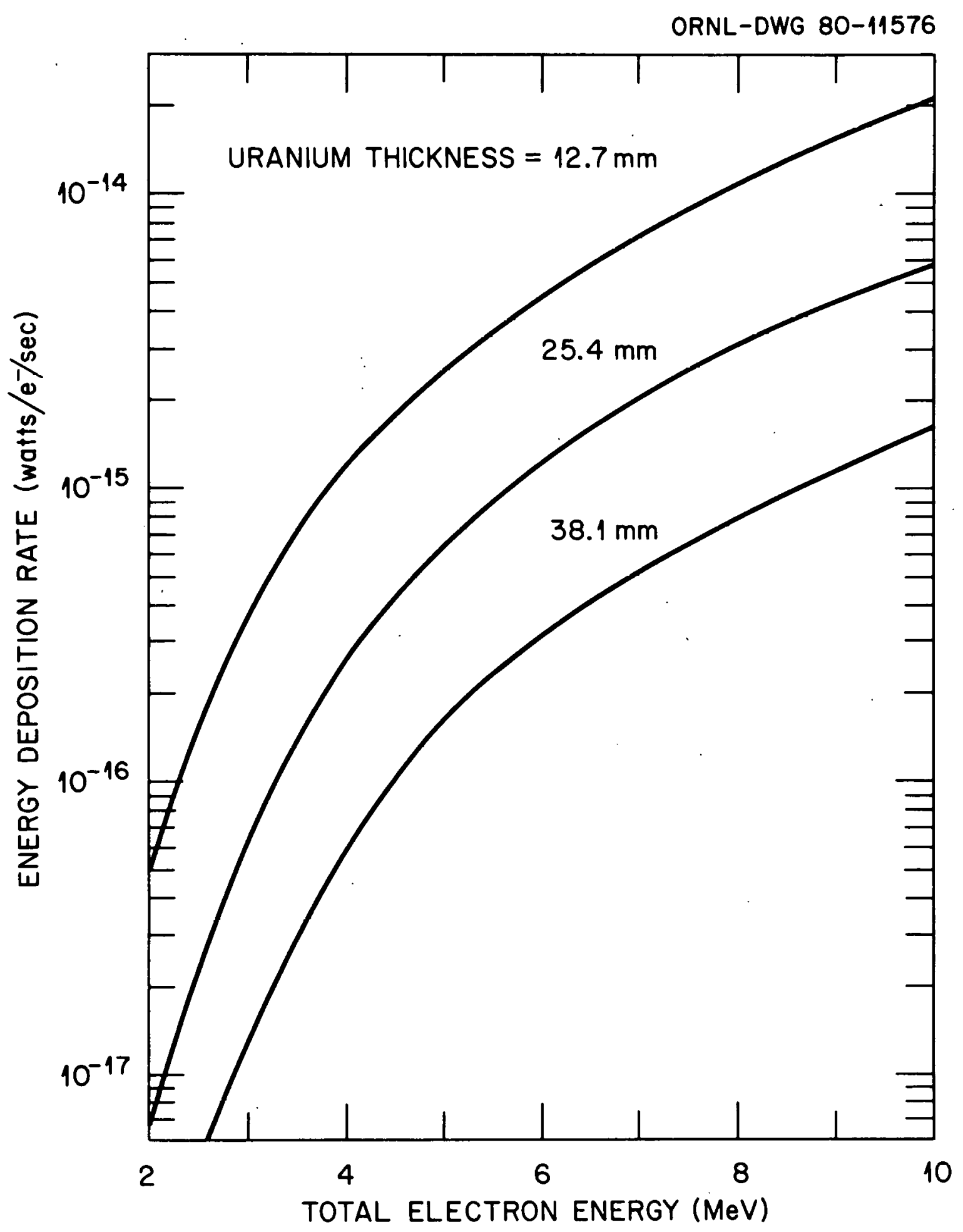

Fig. 2. Energy deposition rates in $\mathrm{Cu}$ coils vs. electron energy for several 238 u coil shield thicknesses. 
data contained in Fig. 2 with an appropriate electron loss distribution. In a likewise manner, other nuclear responses such as biological dose, etc., may be obtained versus electron energy from the spectra listed in Table I. The importance of electron energy to these responses may then be evaluated and each total response may be obtained by weighting these data with an electron loss distribution.

B. Coil Heating

The energy deposition rates in the $\mathrm{Cu}$ coils due to bremsstrahlung gamma rays are presented in Fig. 3 for electron $\mathrm{kT}$ values of $1.0,1.5,2.0$, and $2.0^{*} \mathrm{MeV}$ as a function of coil shield thickness. The energy deposition rate for the tungsten shield was only calculated for a $\mathrm{kT}$ value of $2.0^{*} \mathrm{MeV}$ since this electron temperature produced the greatest heating. These results which have been normalized to a 1 MW electron power loss were obtained using the cumulattve bremsstrahlung spcctra defined by Eq. (2). For a given coil shield thickness and kT value, the energy deposition rate in a single coil can be estimated from these results by simply dividing by the total number of coils.

The energy deposition rates in the $\mathrm{Cu}$ coils due to photoneutron production via $(\gamma, x N)$ and $(\gamma, F)$ reactions in $238_{U}$ and $(\gamma, x N)$ reactions in tungsten was found to be less than 0.1 watt with $31.8 \mathrm{~mm}$ of either ${ }^{238} \mathrm{U}$ or tungsten. Since this value is insignificant compared to the 200 to 400 watts deposited by the bremsstrahlung gamma rays for the same shield thicknesses, 


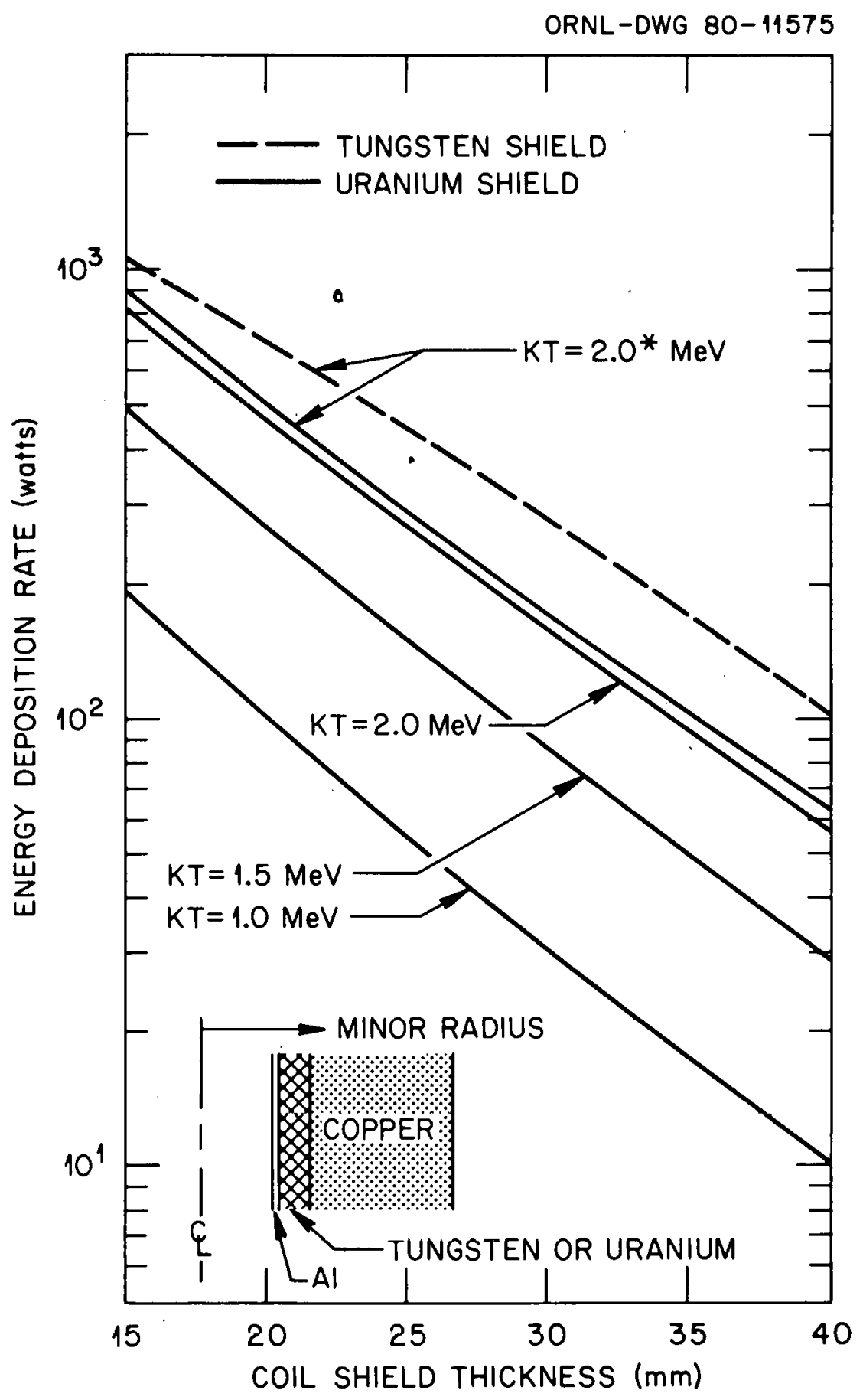

Fig. 3. Energy deposition rate in $\mathrm{Cu}$ coils vs. coil shield thickness for several electron temperatures. 
results were not obtained for varying coil shield thicknesses. The total energy deposition rates in the Al coil liners, ${ }^{238} \mathrm{U}$ coil shields, and $\mathrm{Cu}$ coils for these same electron $\mathrm{kT}$ values and three ${ }^{238} \mathrm{U}$ shield thicknesses are given in Table II. These results have also been normalized to a 1 MW power loss. The energy deposition rates represent only the heating due to bremsstrahlung gamma rays. The heating due to photoneutrons is insignificant as noted above. The remainder of the power loss, i.e., the heating associated with the incident electrons, represents $98 \%$ of the total power 1oss. This portion of the power loss is deposited almost entirely in the Al liners as only a few of the higher energy electrons are able to penetrate into the ${ }^{238} \mathrm{U}$ shield.

The energy deposition rate density profiles across the $\mathrm{Cu}$ coils for an electron $\mathrm{KT}$ value of $2.0^{*} \mathrm{MeV}$ are shown in Fig. 4. These curves have been normalized to one incident electron per second per unit length of Al liner. To obtain the absolute power density for a 1 MW power loss, these results must be multiplied by the electron loss rate corresponding to a kT value of $2.0^{*} \mathrm{MeV}$, i.e., $4.81 \times 10^{18}$ electrons per second, and divided by $2 \pi R_{\text {major, where }} R_{\text {major }}$ represents the major radius of the torus. For example, the maximum power density with the $25.4 \mathrm{~mm}{ }^{238} \mathrm{U}$ shield is 135 watts $/ \mathrm{m}^{3}$ for a major radius of $5.67 \mathrm{~m}$. 
TABLE II

ENERGY DEPOSITION RATE IN COIL MATERIALS (WATTS)

\begin{tabular}{crrrrr}
\hline & & \multicolumn{5}{c}{ Electron } & Temperature & $(\mathrm{MeV})$ \\
Materia1 & $\begin{array}{c}238_{\mathrm{U}} \mathrm{THK} \\
(\mathrm{mm})\end{array}$ & 1.0 & 1.5 & 2.0 & 2.0 \\
\hline \multirow{2}{*}{$\mathrm{A1}^{\mathrm{a}}$} & 12.7 & 2530 & 3260 & 3840 & 3930 \\
& 25.4 & 2520 & 3250 & 3840 & 3930 \\
& 38.1 & 2520 & 3250 & 3830 & 3920 \\
& 12.7 & 6590 & 9670 & 12400 & 12800 \\
& 25.4 & 6830 & 10200 & 13200 & 13700 \\
& 38.1 & 6830 & 10300 & 13400 & 13900 \\
& 12.7 & 260 & 644 & 1080 & 1170 \\
& 25.4 & 54 & 148 & 260 & 285 \\
& 38.1 & 13 & 38 & 68 & 75 \\
& & & & & \\
\hline \hline
\end{tabular}

${ }^{a}$ Energy deposition rate in $A 1$ is due to bremsstrahlung gamma rays on $1 y$. The total energy deposition rate in Al can be estimated by simply subtracting the combined energy deposition rate in $238 \mathrm{U}$ and $\mathrm{Cu}$ from the total power loss of 1 Megawatt. 


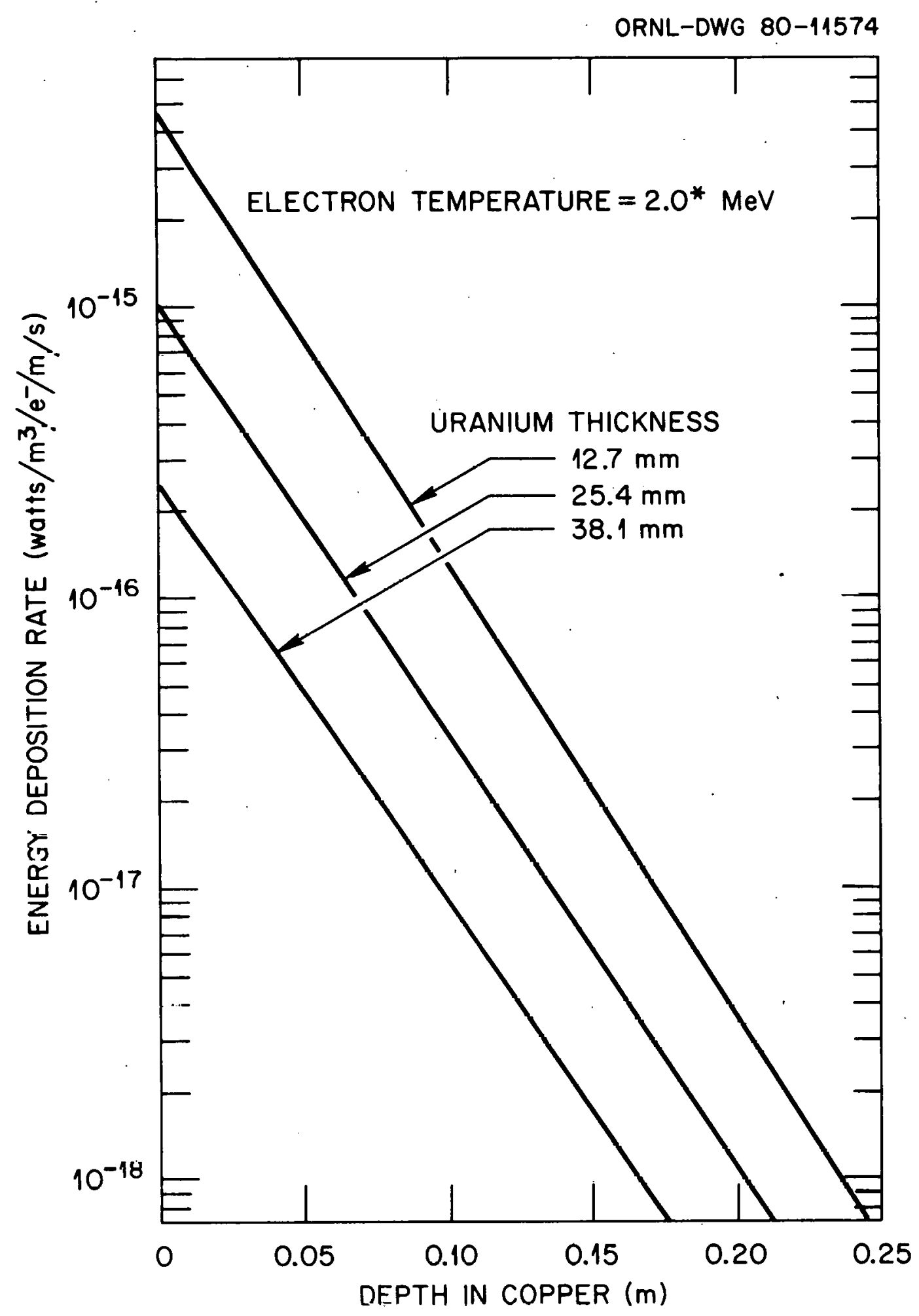

Fig. 4. Normalized energy deposition rate density profiles in $\mathrm{Cu}$ coils for three $238 \mathrm{U}$ shield thicknesses. 


\section{Biological Dose Rates}

The calculated biological dose rates due to bremstrahlung gamma rays are presented as a function of lead and concrete shield thickness in Figs. 5 and 6 , respectively. These results were obtained with and without $31.8 \mathrm{~mm}$ of ${ }^{238_{U}}$ coil shielding for the electron temperatures of interest. The isotropic gamma ray source spectra used in these calculations were the same as those used in the heating calculations and again correspond to a 1 MW electron power loss. For a $\mathrm{kT}$ value of $2.0^{*} \mathrm{MeV}$ in the absence of any ${ }^{238} \mathrm{U}$ coil shielding, $0.318 \mathrm{~m}$ of lead or $1.92 \mathrm{~m}$ of concrete is required to reduce the biological dose rate to $2.5 \mathrm{mrem} / \mathrm{hr}$, which is the maximum radiation level currently accepted.

The biological dose rates due to photoneutron production in a tungsten coil shield are presented in Fig. 7 as a function of lead shield thickness. Also shown is the biological dose rate due to photoneutron production in the lead shield. For a lead shield thickness of $0.30 \mathrm{~m}$, the total dose rate due to photoneutrons and the secondary gamma rays produced by these neutrons is approximately 1500 times greater than the dose rate due to bremsstrahlung gamma rays. This dose rate is dominated by the photoneutrons produced in the tungsten, however, even in the absence of these neutrons, the dose rate due to neutrons produced in the lead shield itself is greater than $100 \mathrm{mrem} / \mathrm{hr}$. At all lead shield thicknesses, the dose rate due to secondary gamma rays is insignficant. 


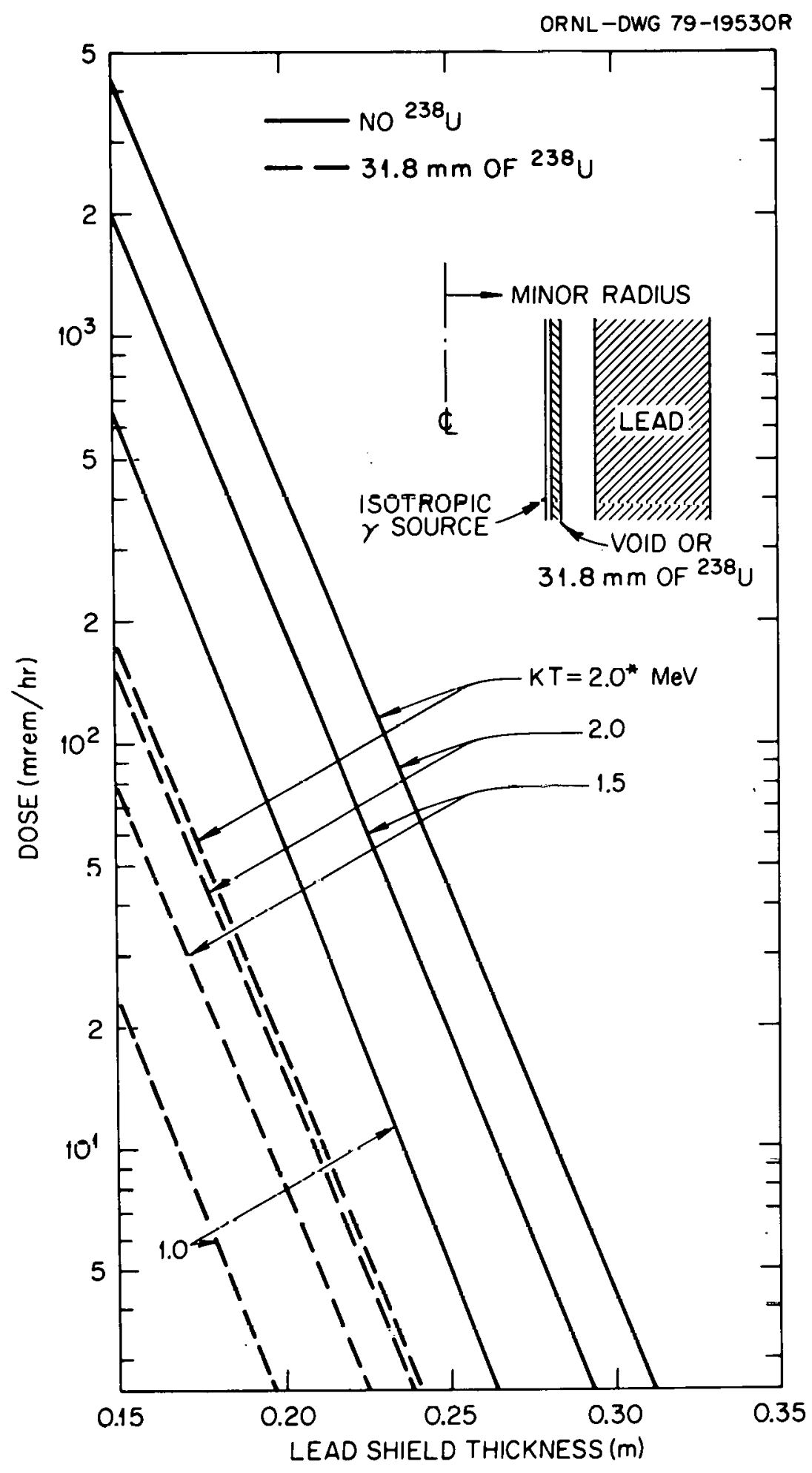

Fig. 5. Biological dose rates vs lcad shield thickness with and without $238 \mathrm{U}$ coil shielding. 


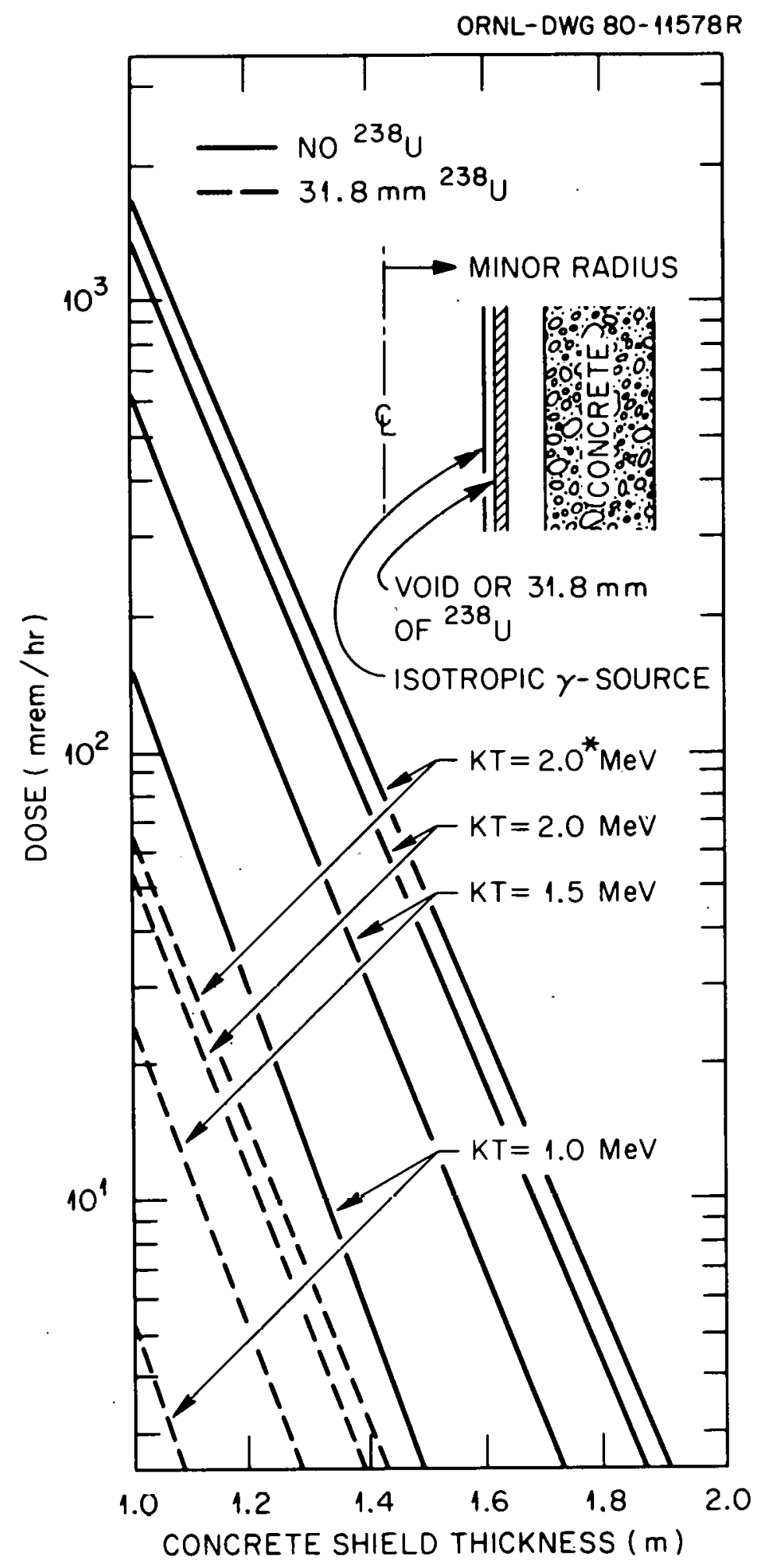

Fig. 6. Biological dose rates vs concrete shield thickness with and without 238 U coil shielding. 


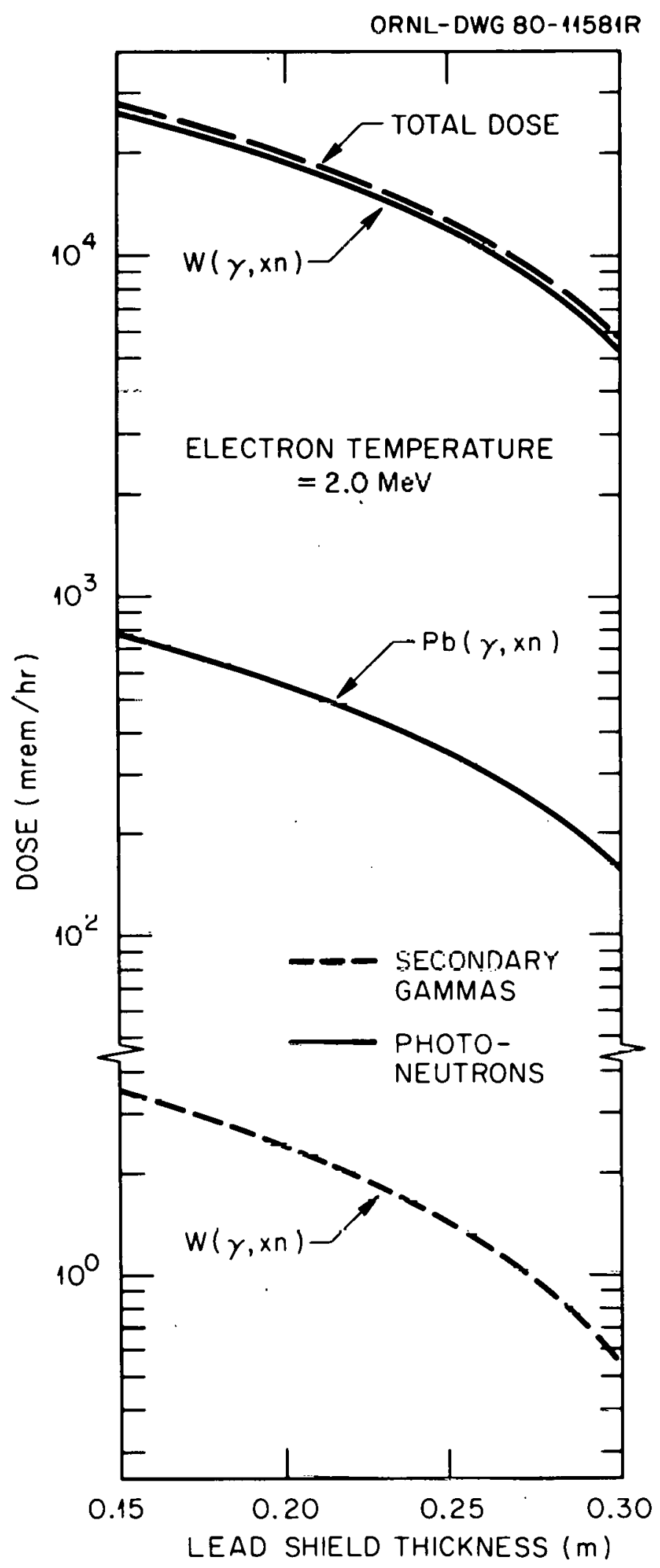

Fig. 7. Biological dose rates due to photoneutron production in tungsten and lead vs. lead shield thickness. 
The total biological dose rate due to photoneutron production in $238 \mathrm{U}$ coil shielding is approximately a factor of two higher than the dose rate when tungsten is used as the shielding material. The factor of two increase in total dose is due entirely to the production of photoneutrons via $(\gamma, F)$ reactions, i.e., photofissions, in the ${ }^{238} \mathrm{U}$. The relative magnitudes of the various contributions are very similar to the tungsten results given in Fig. 7 .

The biological dose rates due to photoneutrons versus concrete shield thickness are presented in Fig. 8 when ${ }^{238} \mathrm{U}$ is used as the coil shielding material. After $1.92 \mathrm{~m}$ of concrete, the total dose rate due to photoneutrons is more than two orders of magnitude lower than the dose rate due to bremstrahlung gamma rays. At concrete thicknesses greater than $1.2 \mathrm{~m}$, the total biological dose rate is primarily due to secondary gamma rays produced in the concrete through inelastic scattering and neutron capture.

In all of the photoneutron calculations, an electron temperature corresponding to a $\mathrm{kT}$ value of $2.0 \mathrm{MeV}$ was employed to obtain the photoneutron production rates. Since this $\mathrm{kT}$ value is representative of the maximum energy anticipated for the electron loss distribution, the biological dose rates in Figs. 7 and 8 should be conservative. In addition, since no reduction in the bremsstrahlung spectra was assumed to occur due to shielding by the components of the machine, the estimated lead and concrete shielding thicknesses 


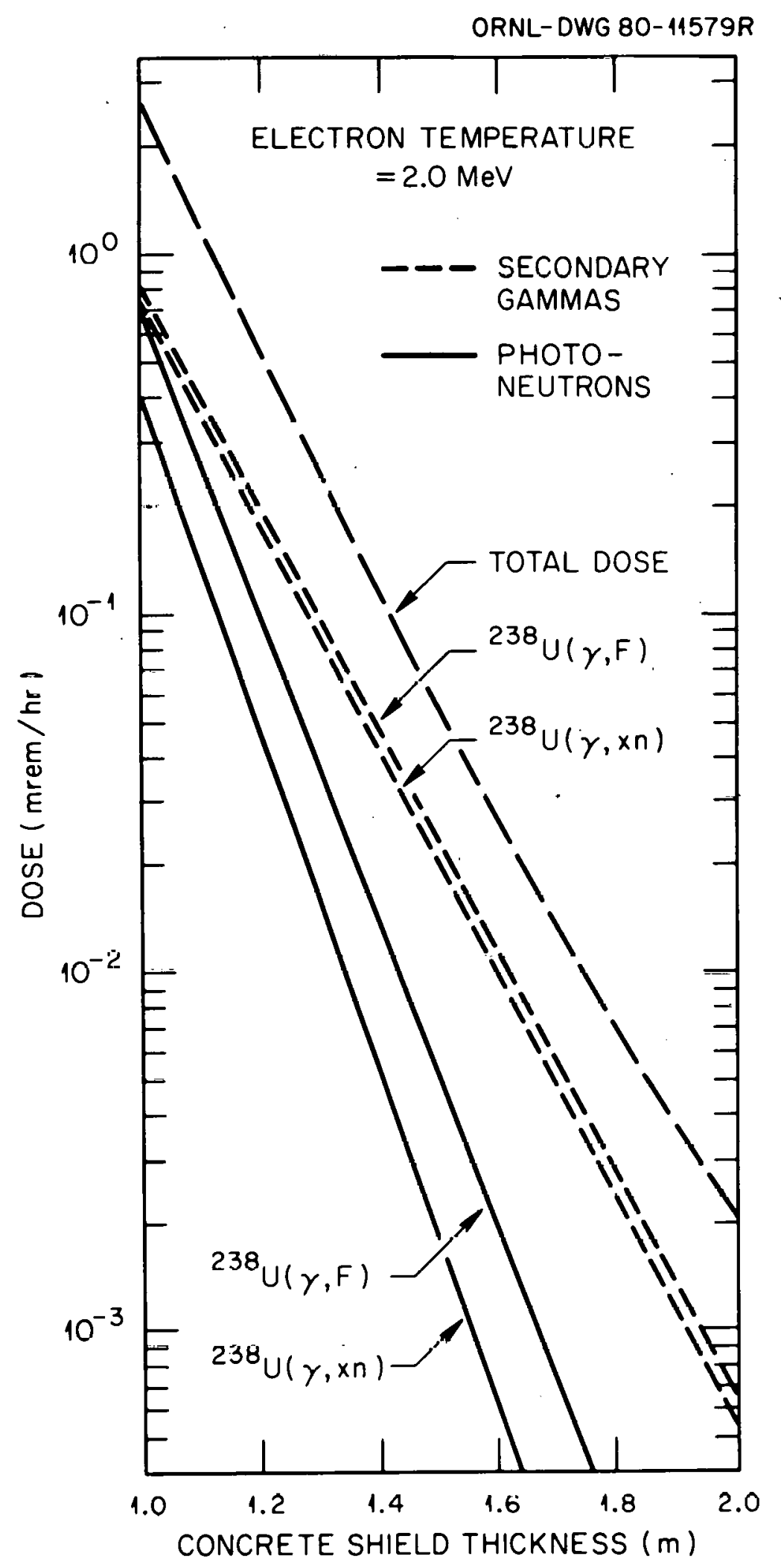

Fig. 8. Biological dose rates due to photoneutron production in $238 \mathrm{U}$ vs. concrete shield thickness. 
required to reduce the biological dose rate due to bremsstrahlung gamma rays to acceptable levels should represent maximum shield thicknesses. However, the photoneutron production which arises because of the high energy bremsstrahlung gamma rays eliminates lead by itself from consideration as a biological shield. 


\section{THIS PAGE}

\section{WAS INTENTIONALLY \\ LEFT BLANK}




\section{References}

1. R. L. Ford and W. R. Nelson, "The EGS Code System: Computer Programs for Monte Carlo Simulation of Electromagnetic Cascade Showers (Version 3)," SLAC-210, Stanford Linear Accelerator Center (1978).

2. W. W. Engle, Jr., "A User's Manual for ANISN, a OneDimensional Discrete Ordinatcs Code with Anisotropic Scattering," ORGDP-K-1693, Oak Ridge Gaseous Diffusion P1ant (1967).

3. D. E. Bartine, J. R. Knight, J. V. Pace, III and R. W. Roussin, "Production and Testing of DNA Few-Group Coupled Neutron-Gamma Cross Section Library," ORNL/TM-4840, Oak Ridge National Laboratory (1977).

4. R. W. Roussin and F.A. R. Schmidt, "Adjoint $S_{n}$ Calculations of Coupled Neutron and Gamma Ray Transport Through Concrete S1abs," Nucl. Eng. \& Design 15, 319 (1971).

5. B. L. Berman, "Atlas of Photoneutron Cross Sections Obtained with Monoenergetic Photons," Atomic Data and Nuclear Data Tables 15, 319-390 (1975).

6. D. M. Parkin and A. N. Goland, "A Computational Method for the Evaluation of Radiation Effects Produced by CTRRelated Neutron Spectra," BNL-50434, Brookhaven National Laboratory (1974).

7. "Evaluated Photon Interaction Library ENDF/B File 23 Format," RSIC Data Library Collection DLC-7, Informal Notes. 
References (Cont'd)

8. N. M. Greene, J. L. Lucius, L. M. Petrie, W. E. Ford, III,

J. E. White and R. Q. Wright, "AMPX: A Modular Code

System for Generating Coupled Multigroup Neutron-Gamma

Libraries from ENDF/B," ORNL/TM-3706, Oak Ridge National Laboratory (1976).

9. Y. Gohar and M. A. Abdou, "MACKLIB-IV: A Library of Nuclear Response Funlions Gencrated with the MACK=IV Computer Program from ENDF/B-IV," ANL/FPP/TM-106, Argonne National Laboratory (1978). 
ORNL/TM-7136
Dist. Category UC-20d

\section{Internal Distribution}

\begin{tabular}{|c|c|c|c|}
\hline $\begin{array}{r}1-2 . \\
3 . \\
4 . \\
5 . \\
6 . \\
7 . \\
8 . \\
9 . \\
-12 . \\
3-25 . \\
26 . \\
27 . \\
28 . \\
29 \\
30 . \\
31 . \\
32 . \\
33 . \\
-36 . \\
37 . \\
38 .\end{array}$ & $\begin{array}{l}\text { L. S. Abbott } \\
\text { F. S. Alsmiller } \\
\text { R. G. Alsmiller, } \\
\text { J. Barish } \\
\text { J. M. Barnes } \\
\text { D. E. Bartine } \\
\text { L. A. Berry } \\
\text { W. B. Bigney } \\
\text { B. L. Bishop } \\
\text { A. L. Boch } \\
\text { R. A. Brown } \\
\text { J. A. Cobble } \\
\text { R. J. Colchin } \\
\text { R. A. Dory } \\
\text { H. O. Eason, Jr. } \\
\text { O. C. Eldridge } \\
\text { G. F. Flanagan } \\
\text { W. M. Fletcher } \\
\text { T. A. Gabrie1 } \\
\text { J. C. Glowienka } \\
\text { H. Goldstein. } \\
\text { (Consultant) } \\
\text { H. H. Haselton } \\
\text { G. R. Haste, Jr. } \\
\text { R. A. Lilie } \\
\text { F. C. Maienschein } \\
\text { H. C. McCurdy } \\
\text { T. J. McManamy } \\
\text { R. A. Michelotti } \\
\text { R. W. Peelle }\end{array}$ & $\begin{array}{l}51 . \\
52 . \\
53 . \\
54 . \\
55 . \\
56 . \\
57 . \\
58 . \\
59 . \\
60 . \\
61 . \\
62 . \\
63 .\end{array}$ & $\begin{array}{l}\text { W. H. Power } \\
\text { R. K. Richards } \\
\text { R. W. Roussin } \\
\text { M. W. Rosenthal } \\
\text { RSIC } \\
\text { R. T. Santoro } \\
\text { J. Sheffield } \\
\text { J. D. Stout } \\
\text { N. A. Uckan } \\
\text { C. R. Weisbin } \\
\text { A. Zucker } \\
\text { P. Greebler (Consultant) } \\
\text { H. J. C. Kouts } \\
\text { (Consultant) } \\
\text { W. B. Loewenstein } \\
\text { (Consultant) } \\
\text { R. Wilson (Consultant) } \\
\text { Central Research Library } \\
\text { ORNL Y-12 Technical } \\
\text { Library - Document } \\
\text { Reference Section } \\
\text { Laboratory Records Dept. } \\
\text { ORNL Patent Office } \\
\text { Laboratory Records - RC }\end{array}$ \\
\hline
\end{tabular}

\section{External Distribtion}

72. Office of Assistant Manager, Energy Research and Development, DOE-ORO, Oak Ridge, TN 37830

73-75. V. C. Baker, General Dynamics, P.0. Box 2507, Mai1 Zone 423-1, Pomona, CA 91766

76. F. E. Coffman, Chief, Systems and Applications Studies Branch, Office of Fusion Energy, U.S. Dept. of Energy, Washington, DC 20545

77. R. Ng, Office of Fusion Energy, U.S. Dept. of Energy, Washington, DC 20545

78-215. Given distribution as shown in TID-4500, Magnetic Fusion Energy (Distribution Category UC-20d:

Fusion Systems) 